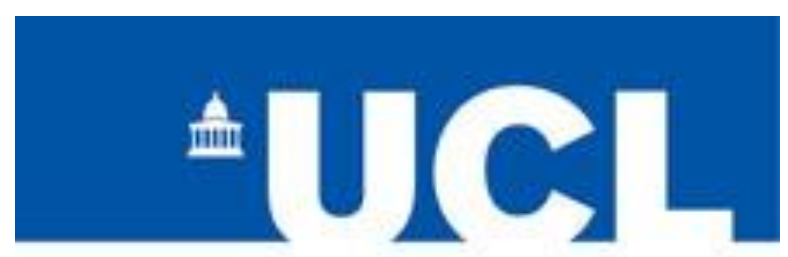

\title{
Institute of Education
}

The Impact on a Primary School Community in England of Failed Inspection and Subsequent Academisation

by

\author{
Jacqueline Elton \& Trevor Male \\ (UCL Institute of Education)
}

[School Leadership and Management. Online 17 July, 2015. DOI: 10.1080/13632434.2015.1053860]

Correspondence:

Dr. Trevor Male

London Centre for Leadership in Learning,

UCL Institute of Education,

20 Bedford Way,

London.

WC1H OAL

ENGLAND

T: +44 (0)207 6126284

E: t.male@ucl.ac.uk

@maletrevor 


\title{
The Impact on a Primary School Community in England of Failed Inspection and Subsequent Academisation
}

\author{
Jacqueline Elton \& Trevor Male \\ (UCL Institute of Education)
}

\begin{abstract}
This research reports upon the impact of two concurrent processes of Special Measures and academisation applied to a primary school in the north of England as a result of an unsatisfactory inspection by the Office for Standards in Education (Ofsted). The aim of the study is to describe how the process of being placed in special measures, coupled with subsequent academisation, affected key "school facing" stakeholders. Data collection commenced from when the school received the judgement about its performance from Ofsted. This paper will examine the emerging themes during the first phase of the process of school transformation.
\end{abstract}

\section{Introduction}

This is an investigation of the impact on members of an English primary school community as it went through the transformation to an academy following an inspection by the Office for Standards in Education (Ofsted) in 2012 that identified the school as inadequate in three of the four categories and subsequently placed in Special Measures. The option to convert to academy status that had become available to the Secretary of State following changes in legislation was invoked, leaving the school community facing twin interventions into their work as they faced the demands of responding to the category of Special Measures whilst at the same time being subject to the academisation process.

The research was undertaken by two researchers from the local university and reports on the impact on key school facing stakeholders of the early stages of the parallel processes of responding to Special Measures and becoming an academy. In this context "school facing" is defined as those charged with delivering the educational service to the user groups of the school and consisted of members of the school community (the headteacher, senior leaders, support staff and governors) or were employed by the local authority (School Improvement Advisor). The principal researcher was also a stakeholder, having been a member of the school governing body at the time of the Ofsted inspection in 2012. This gave rise to issues 
relating to concepts of insider-outsider research which had to be addressed in order to report accurately and, as far as possible, evenly on the findings.

The enquiry shows most school facing stakeholders considering they did not have adequate opportunity to influence subsequent events. The twin processes seemed to apply a multiplying rather than cumulative effect, particularly on members of the school workforce who report feeling devalued, de-professionalised and ultimately working in a climate of fear.

\section{Macademia Primary School}

At the time of the conversion to academy status the school was a mixed gender primary community school based in a city in the North of England and was larger than average size with 536 pupils aged 3 to 11 years. Almost all pupils were of White British heritage with the proportion of pupils known to be eligible for the Pupil Premium being below national and local average. The proportion of pupils supported through School Action and School Action Plus (government policies for children with learning difficulties) were below national and local average as is those with a statement of special educational needs.

\section{Methodology}

The most relevant methodology was considered to be that of an interpretive case study as the research sought holistic answers to a series of 'what' and 'how' questions in relation to the effects on user groups of the external application of the two concurrent processes of Special Measures and required academisation, the combination of which to date are relatively uncharted.

The key research questions adopted were:

- What were the perceptions of the "school facing" stakeholders of the twin processes of being placed in Special Measures and the concurrent academisation process?

- How have these two processes affected these stakeholder groups?

A case study design allowed the study of a contemporary phenomenon within its real-life context by making use of multiple sources of evidence. At the 
conceptualisation stage, therefore, it was envisaged that the data would be collected spanning the time period from the commencement of Special Measures to, if possible, a full year after the school had undergone academisation in order to fully chart the effect of the processes on the key school facing groups.

The principal researcher had participated as a member in the initial series of extraordinary governing body meetings convened to consider the implications of the situation arising from the Ofsted report and the concept of eligibility for intervention available to the Secretary of State and had recognised the opportunity to chart the subsequent impact on the school community. She was able to secure the support of the then major actors within the school including both the headteacher and the Chair of Governors, who not only gave permission for the research study to proceed, but were able to facilitate the interview part of the field work during school time. Whilst the main part of the field work commenced in January 2013, the researchers were also able to access participant data and documentation retrospectively, going back to the date of the Ofsted inspection in November 2012.

The key data collection tool employed to enable the 'thick description' (Geertz, 1973) necessitated by the interpretivist paradigm was that of interviews, supplemented by analysis of relevant school documentation. Of the different types of interview formats available, semi-structured interviews were selected as they allowed for new questions, follow up replies, departures from the schedule or even the reinterviewing of participants if necessary.

The study was opportunistic in its nature, in that the project "found" the researchers. Both researchers were from the Faculty of Education in the local university, with the principal researcher having been a member of the governing body of the school since 2009. This gave rise, of course, to matters relating to insider-outsider research as her twin role as governor and researcher could have easily led to the situation in which she could "not escape her past" (Mercer, 2007: 15). In other words participants in the planned research could have been affected by her position as governor and in the worst case could have perceived themselves as being required to provide the answers that an opponent of academisation would expect. There are also concerns in this regard to the possibility of participants saying more to the 
'insider' than they would say to someone they did not know so well. In short the nature of governor-researcher could have led in some instances to subject coercion, compliance and [over] access to privileged information (Smyth \& Holian, 2008). Conversely, however, it needs to be equally recognised that the quality of data may have been much richer as a consequence of having "an established intimacy which promotes both the telling and the judging of truth" (Unluer, 2012: 1). In part these issues were addressed through the relationship of the second researcher to the project. He had not had previous contact with members of the school community and could be assessed as being capable of interpreting the data as it was presented when the insider may have seen what she wanted to see. In working this issue through the principal researcher operated more in line with what Humphrey (2007) calls the 'insider-outsider continuum' and the effects of being, as she puts it, on the 'hyphen' between being an insider and an outsider. Consequently the principal researcher sought to verify the data in a number of ways, with the second researcher being able to operate as a critical friend when interpreting the data.

\section{The Context of Data Collection}

All schools in England are required to be inspected by Ofsted under section 5 of the Education Act 2005 (as amended) within a five year period, with the exception of a small number of private schools and schools deemed 'exempt' (having been judged as Outstanding in a previous Section 5 inspection), The third of the four categories of judgement (Outstanding, Good, Satisfactory and Needs Improvement) was amended in September 2012 from 'satisfactory' to 'requires improvement'. This was of direct importance to the state maintained school that features in this research, Macademia Primary, which had emerged from an Ofsted Inspection in January 2011 with a grade of 'satisfactory', with the report painting an optimistic picture for the school going forward and conditions for "rapid improvement" having been noted (Ofsted, 2011, p.13). The trigger for enacting a second report in 2012 was that the school encountered severe budgetary pressures caused by an inherited, significant and otherwise unbeknown overspend on the budget. In the interview conducted with him for this research the attached School Improvement Adviser reported this was only discovered after a change of headship in 2011 which left the current headteacher dealing with a budget deficit and overstaffing. This led the Local Authority (LA), the body responsible for oversight of school provision within the area, 
to invoke their statutory powers to serve the governing body with a warning notice in relation to the future removal of the delegated budget should the deficit issue remain unaddressed. This warning notice persisted even though the governors' and headteacher's efforts at the deficit reduction soon became successful.

In September 2012 a new Ofsted inspection was ordered (under the newly revised Inspection Framework) which resulted in the school being categorised as 'inadequate', the lowest category, and being placed in Special Measures. A school placed in this category is deemed to be failing to give its pupils an acceptable standard of education with the leaders, managers or governors not demonstrating the capacity to secure the necessary improvement in the school. This made the school prone to an opportunity for the Secretary of State to require it to change its status as amendments to the Academies Act of 2010 permitted him to make underperforming state maintained schools become an academy.

Until 2011, only in severe cases of lack of school turnaround at the end of the two year process of Special Measures was the final solution of structural change adopted by the DfE in relation to tackling school underperformance. Amendments to the 2011 Education Act and Section 4 of the Academies Act of 2010, however, allowed the Secretary of State to make an intervention on any maintained school which falls into any of one of the following three specific categories:

1. Where the local authority has given the governing body a warning notice in relation to low standards of performance at the school, a serious breakdown in management or governance which is prejudicing standards of performance, or a risk to the safety of pupils or staff due to a breakdown in discipline and the school has failed to comply with the warning notice to the satisfaction of the authority;

2. When a maintained school requires 'significant improvement' if, following an inspection of the school, Ofsted has given notice that the school requires 'significant improvement';

3. Where a maintained school requires 'special measures' if, following an inspection of the school, Ofsted has given notice that the school requires special measures.

Academies are publicly funded independent schools which do not have to follow the national curriculum and can set their own term times. They still have to follow the same rules on admissions, special educational needs and pupil exclusions as other 
state schools, but get money direct from central government and not the local council. The policy intention behind the establishment of academies was to address the problem of entrenched failure within English schools with low academic achievement, or schools situated in communities with low academic aspirations. They were expected to be creative and innovative because of their financial and academic freedoms in order to deal with the long-term issues they were intended to solve. There has been a rapid increase in the number of schools becoming academies since the election of a coalition government in 2010 , however, with the Secretary of State for Education advocating schools to take this new status and, in some instances, through enacting the new legislation to effect academisation.

Upon conversion to an academy the school will become independent of the local authority and will be managed by a sponsor who will become proprietor. For those being required to become academies the process of conversion will then follow the same route as a school that has voluntarily chosen to have that status. Consultation will take place by the proposed new academy proprietor which the Secretary of State will consider before confirming the Academy Order and setting the conversion date. Then the academy arrangements and funding agreements will be made with the proprietor prior to re-opening as an academy.

Although the school had been in Special Measures since November 2012 and the Governors had already appointed the new academy sponsors, that process was handled in such a way that there was no real debate. The consultation sessions between preferred sponsor and parents were scheduled on a Monday at 11.00 and 14.00, for example, but was only announced on the preceding Friday. A situation which marginalized working parents as one governor comments:

We found out about this on the Friday that they were doing it on the Monday. Apparently they had been informed we have a large working family intake and those are the ones that will want to come and you're not making yourself available for them. And it was like: "That's when we're doing it and that's that!". They didn't give a hoot.

This period also saw the manifestation of the impact of the Special Measures processes rather than any substantial mass application of the academisation 
processes: the latter processes were instead, mainly directed at the headteacher and the IEB. It left the headteacher, however, on his own calculation having to spend much of his time responding to the twin processes:

[...] each session takes at least a day's preparation to prepare for the paperwork and levels of accountability that's wanted. Over a five-week period, which is 25 working days, there's probably been in excess of ten days of either doing the accountability or preparing for the accountability. That's over 50 per cent of my time just being accountable.

In the second half term, from March to April 2013, the school was in second stage of Special Measures processes and layered upon this, the academisation processes began to filter down to staff. This period could best be entitled as the "it's not going away" phase of the processes, involving HMI monitoring visits, the establishment of the IEB, school to school support and the academisation consultation. Five more members of the school workforce were interviewed in this phase, two teachers and three members of support staff, together with the Chair of Governors and the local authority attached School Improvement Advisor. In the third half-term, from April to July,2013, three governors - two Parent and one Community - were interviewed in relation to the same range of issues highlighted above, but whilst the academisation process was being finalised.

Throughout the period of data collection the members of the school community were thus in the uncommon position of being unwilling participants in the contemporaneous processes of being responsive to the demands of Special Measures whilst also subject to the academisation process. This placed key members of the school community, particularly the headteacher and governors, in a situation where they were being required to respond to school improvement expectations led by members of Her Majesty's Inspectorate (HMI) whilst also subject to effectively being taken over by the tenets of the academisation process.

Once a school goes into Special Measures, particular processes are always invoked: the local authority is required to prepare and have approved a school improvement plan which addresses the concerns and recommendations of the Ofsted report. Her Majesty's Inspectors (HMI) subsequently visit the school regularly to monitor and report upon the school's performance against the improvement plan. Typically the 
school is also linked to another local school which is considered to be successful and from which the school deemed 'inadequate' can draw on their expertise.

Furthermore, schools in Special Measures are subject to statutory powers provided to local authorities which include the removal of the Governing Body and the imposition of an Interim Executive Board (IEB), the membership of whom is selected for by the LA (but paid for by the school). Events at Macademia followed this pattern over the course of the period after the publication of the Ofsted report including suspension of the governing body and the appointment of an IEB by April 2013.

Schools moving into academy status are normally expected to identify a sponsor and work closely with them to establish new governance and management structures that will allow them to operate as an independent organisation. Such processes assume a choice has been made to convert to academy status, but in the case of a required academisation the school would have little influence on the choice of sponsor, which is what happened in this case with the local authority.

The consequences for the school were that whilst HMI were monitoring the action plan (which included partnering with another local school) an IEB took over governor responsibilities and led the process of academisation with a sponsor that was effectively appointed to the school, rather than chosen. There was a considerable impact on the role and workload of headteacher during this period as has been described above.

\section{Data Collection}

In total there were 16 Individual semi-structured, audio recorded interviews conducted with 10 members of teaching and support staff, the headteacher, four governors (including the Chair) and the local authority's attached School Improvement Adviser. Each interview lasted between 30 minutes and an hour and was conducted during the first two terms of the period of Special Measures and academisation. The headteacher and five teachers were interviewed during this first phase, although the governors had been removed by the local authority in December 2012 and replaced with an Interim Executive Board (IEB), which restricted their involvement. At this stage the headteacher had asked the researcher to defer the 
planned interviews of the parents and pupils until after the academisation consultation process had been formally commenced with parents. Subsequently, however, a new interim headteacher was appointed shortly after the end of the consultation period and all the school based data collection ceased at this point. Consequently this paper can only report on the findings up to July 2013.

\section{Data analysis}

There were two major foci of data analysis - those referring to the application of Special Measures and those referring to the impact of 'academisation'.

\section{The effects of Special Measures}

Teachers and support staff were keen to recount their experiences of the inspection and offer their opinion as to what caused or contributed to the final Ofsted judgment of 'inadequate'. It was a period characterized by feelings of shock and their feelings are encapsulated by one teacher who described the inspection process form their perspective:

It was the most horrendous day. [Whispering] During the day you're asking is it going well here, is it going well there? Well no. Last time it was all positive and in my area wonderful, really great and very positive, not that an inspection is ever a nice day, but this time it wasn't a nice day. You get a vibe during the day and everyone knows what it means. No words need to be spoken; the body language is the key. Everyone came to the conclusion that it hadn't gone well.

Such feelings were sustained throughout the period of data collection with teachers and support staff vociferously contesting the Ofsted judgement. Only one teacher said that they thought the judgment was relatively fair, with the remaining interviewees reporting a strong belief that the Ofsted judgment was "wrong" and experiencing difficulty in believing that the school deserved its "failing" label. Typical of those responses were the feelings of a member of support staff:

I rated the school as a good, actually a really good school. I'm not an expert but I think the Ofsted judgement was unfair. It was harsh, very harsh! Staff work hard, plan, plan, plan and deliver good lessons. I go all around the school and see all teacher lessons and some of the Ofsted judgment's for lesson observations don't make sense for me. The Ofsted judgements on the lesson observations aren't fair. I see all the things they do with the children. 
There was a large amount of discussion of the new post-Ofsted scenario, with staff commenting on how they felt the processes were affecting them in a personal capacity. A typical reaction was demonstrated by the connected thoughts of one teacher that emerged throughout the course of a one hour interview:

I think that there's a lot of pressure put on people who then put pressure on you. [...] Friendships and work relationships are very tense now, very, very tense now and you take it all home. [...] Before it was a team and a joy to work here and there were lots of smiles. I used to look forward to coming to work. [...] School used to be my outlet and I thrived, but now it's not that, it's a grind and a burden. [...] I feel flat, very flat at the moment. I feel that my face doesn't fit here anymore. [...] Everyone is looking after themselves. It's all very unpleasant especially for someone like me who used to find work their escape. [...] I feel out of control. I feel like a pawn in a bigger game. [...] You hope things will change and you think it's just a period that you are going through, but it's not. It's going to be like this for quite a while. It's whether you are strong enough to ride it out. I don't think that I am. [...] I feel completely exhausted. This is the first week I haven't gone home and cried all week. [...] It's just horrendous. Not a nice place to be in at the moment. [...] I feel like a failure right now. [...] I can't see any way out of here - it's hard. I feel stifled. I feel like I've had all the stuffing kicked out of me.

The category which drew the most overall comment was that of being categorised or graded on the lesson evaluation scale and this reflected the notion that although Ofsted insist it is the lesson that is judged, in reality the teachers feel that they themselves are being judged. Surprisingly, even though the grading of lessons do not apply to the support staff, they still felt as if they did. All support staff who commented took the grading as a reflection of their own performance, when in reality it is the teacher who takes the responsibility for the performance of the support staff in their lessons.

There's the added pressure, am I going it right. If you get "requires improvement" you think am I doing it wrong? Self-doubt has crept in that wasn't there before. [Support staff]

A colleague has been put on "Unsatisfactory", there's no way she's "Unsatisfactory", possibly "Requires Improvement" maybe. [Teacher]

You suddenly start to realise that this is a game, there's no way that was a "Requires Improvement" lesson [Teacher]

Teachers discussed at some considerable length how the processes were making them reflect on their professional selves and how this affected their hitherto held 
beliefs in their capabilities as competent or "good" teachers. One teacher explained how the staff had been told that teacher talk was no longer acceptable in lessons, other than in tiny and separated amounts:

Sometimes now when I am talking I feel upset about the fact that I am talking and thinking. Oh no, am I really a bad teacher, I'm talking to my kids? That's the effect it had, we're all desperate not to talk to them now.

Two teachers discussed concerns around the increased regime of lesson observations and the how difficult and unpleasant they found the process of being observed with both gravitating towards the opinion that having been buffeted around by rapidly changing notions of "what is right" and "what works" in the early days, coupled with the ever-present substantial lesson observation regime, they had effectively lost their pedagogical compass and professional confidence. It would seem that as the staff got more desensitised to this pedagogical uncertainty and the associated scrutiny, these two faculties started to return. Only one teacher reported that he had now settled upon his own personal conceptions of what good teaching was and was confident enough to get on with it in the classroom even to the point of taking on any challengers very much in the vein of the adage - 'what doesn't kill you makes you stronger'.

Teaching staff indicated they were unhappy about the relationship with the partner school which placed them in role of second order practitioners where before they had been able to make decisions and judgements based on their own expertise. This was particularly uncomfortable for those who believed the partner school was being judged as 'good' on the previous inspection schedule and had not been exposed to the new Ofsted inspection framework. Typical of these feelings are the responses from two of the teachers at Macademia:

For part of our professional development process now we have to be observed as a part of the process. [...] I felt that the observation process was intrusive. I felt that I had had more observations on one day than was legally allowed [...]. With the removal of the satisfactory grade there's not much room now between passing and failing as a teacher.

I was observed by teacher from Partner school who said that I needed a TA in the classroom. This how I feel you can't win. It's a limiting factor. Without it 
being addressed I will never get a "good". It's frustrating that this stuff is beyond my control, but I'm still being judged on it.

All staff felt a sense of frustration and more negative feelings at the extent of third party involvement in the school. The comments centred on the belief that the partner primary school and the local authority were often contradicting each other with the improvement advice they were giving and there was also a sense that the advice conflicted with what they had previously understood to be good practice as one teacher commented:

Now there's eyes everywhere ... That pressure will make you slip up and make you do things you wouldn't normally do. Different people are telling you different things. People say do it this way and then someone else says no, do it that way instead ... [The partner primary] are due to be observed aren't they and they are expected to get an outstanding I think? I went to observe them, l've always been told, I think for 4 Year olds 10 minutes on the carpet is quite adequate -35 minutes! They kept their children on the carpet for 35 minutes. It's too long. You are taught children off the carpet in 10 minutes, so 35 minutes on the carpet? It's not what l've been taught.

The feeling of being de-professionalised and subject to forces beyond their control was a general feeling amongst teaching and support staff who thus saw themselves as fighting to save their jobs, rather than resisting the changes. In addition to the staff comments probably the most painful experience of this data collection, however, was the interview with the serving headteacher. He asked:

Which other professions go through this? It is a humiliating process and part of me thinks that if the government was truly focused on school improvement they could think of a much more effective and streamlined way of doing things. I think it's a sanitisation process and very similar to a form of ethnic cleansing in that you're seen to be a Special Measures school so as a result of that you will be put through this ritual. I think there's an element there of job justification and also an element of bayoneting the dead in that, it's "Oh, well, they're fair game so we'll go in there and we'll be seen to be making them accountable".

The thoughts and feelings of the headteacher thus provide a summary statement of the staff and school community response to being categorised as 'inadequate' and placed in Special Measures after the more positive outcome of the previous inspection conducted just 18 months before in January 2011. 


\section{The Impact of Academisation}

In many ways it could be argued that the experiences of the school community to the impact of Special Measures were not unusual, as painful as they were to those involved, as many other schools have been engaged in similar circumstances on being judged as 'inadequate'. What made this case different was the additional and contemporaneous order to become an academy.

In the early stages members of the school community talked at length about the notion that either the local authority or the school had been targeted for improvement and academisation. Perceptions surfaced of a conspiracy towards the local authority, even a sense of persecution, and it was common belief that the removal or reduction of the local authority was a motive. Many felt that consequently Ofsted were coming in with a pre-determined agenda, a situation summed up thus by one teacher:

l'd heard by talking to colleagues at other schools and reading that [our LA] and [another city] weren't doing very well and that Ofsted were coming into force schools to academies. After Ofsted, matching our experience with rumours, a colleague spoke about the negative view of the city and that they were coming into change it - they're coming in on that agenda. They were here on a mission.

The 'normal' process of appointing an academy sponsor was perhaps blighted by that backdrop, but was seriously compromised from the local community's point of view when the governing body was unceremoniously dismissed via an email message three days before the end of the first term. Having met with a representative of the preferred sponsor members of the governing body, particularly parents, were reasonably enthusiastic about the future of the school according to the then Chair and went away from the meeting believing they were going to continue in their role when academy status was achieved. Instead they were replaced by an IEB consisting of two local ex-headteachers and a former employee of a government agency who was skilled in financial management. This seemed to generate feelings of helplessness and, with it, frustration and disillusionment from parent governors who were seemingly hurt by this as described by the former Chair of Governors: 
So this almost felt like a stab in the back because it was, "Well, goodbye and thank you very much". I think they felt it quite deeply, that they were being shuffled off and also that meant that they then had no tenure, no stake, no say, and that, for parent governors, is quite important.

Their earlier enthusiasm seemed to give way to cynicism and a determination not to get involved again in the future. The requirements of the new governing body, the Chair suggested, was perceived to be more professional and "business-like" than had been the case when members were local volunteers. Parents withdrew and the process of appointing the sponsor and the subsequent allocation of leadership and management responsibilities within the school was undertaken by the IEB and the sponsor. The work and decision making of the headteacher and other senior staff was monitored by the partner school, an outcome which seriously affected morale within the school workforce according to former Chair:

[Staff] took it very personally [and] it caused a huge amount of stress, personal stress. Some of them have been here a long time and I think they took it considerably worse than the younger ones, who maybe were more exposed to the tighter regimes that Ofsted had. But, it made them feel wretched; I can't say anything else. They were absolutely on the floor and nobody could bring anybody else up, because they were all on the floor.

The consequence for both the school workforce and parents was to become much more self-oriented, to the detriment of community spirit. Their feelings about the school soon gave way to concerns about job security from the staff and continued adequate provision for students from parents and community members. For example, the main pre-occupation of employed staff who were interviewed, but especially so for all the three members of support staff, was whether they would keep their jobs, whether they would be expected to do more for less and what might happen after the Academy was no longer required to follow statutory pay and conditions legislation. The concerns were expressed by two members of support staff in the following comments:

It's really about whether we keep our jobs isn't it. Are we going to be in the same job are we going to keep the same pay, the same pay scale? There could be some extra resources versus a job or not. If yes, where am I going to be put? But it's what level are you going to be put, what status? It's a worry if someone else brought in as the headteacher because they will not know you. 
But is it better the devil you know? If you have to reapply, will you be on the same pay-scale and the same pay? Are they wanting more out of you for the same money or for less money?

Happy to work in the academy if offered a job, just happy to have a job.

The concerns of parents shifted during this period as well with them becoming "just basically resigned to the fact that if that's what's going to happen, that's what's going to happen", according to the original headteacher in his interview. Parents, he concluded, seemed more concerned as the academisation process continued with very direct questions about the welfare and prospects of their children rather than dissatisfaction with the policy implementation. Key and frequent questions were:

- Will the provision of the service be affected in any way?

- Is the school open the same number of hours, and

- Will the child's teacher be changed'?

Their concerns were thus less to do with sustaining the previous school environment and more to do with personal issues, he concluded:

I think so long as the frontline service is the same I don't think the parents' are going to be that bothered. Now if we were to say that the new school day would be $7.30 \mathrm{am}$ to $1.30 \mathrm{pm}$ that would have a huge impact. So it's not had a huge impact with the parents at all. I've had a couple of the more professional parents come to have a chat with me, but other than that, our relationship's almost the same.

The requirements to address the twin impact of Special Measures and academisation produced, however, a near impossible task of balancing the focus of headteacher and senior staff effort to improve. Schools in Special Measures have to address issues required by both the LA and the HMI team which are supposed to be focused on teaching and learning, yet at the same time this school was required to attend to a further set of expectations emanating from the sponsors and the $\mathrm{HMI}$ team associated with the academisation process. This, suggested the attached LA School Improvement Adviser, could be deemed to be overly demanding:

The academy agenda is actually taking the headteacher's focus away from teaching and learning because they've got to engage with seeking a sponsor who are sending people in to do two day inspections. So actually that 
process itself derails schools from the key focus of teaching and learning. Meanwhile for schools in Special Measures the LA require a blank file review at the end of term, which is all the key people within the school getting together to talk about the progress of the school. In the past month, Macademia have had a two day HMI inspection [related to Special Measures] and a two day visit from an HMI sent in by the sponsor. They've had a full morning grilling about data and stuff from DFE officials and then they've had the Local Authority blank file review. Now all of those four things have happened within a three to four week school period. Now that's just absolutely crazy.

Sadly we were unable to follow up on these issues further with the headteacher who effectively disappeared. No details of his changed circumstances have ever been published by the local authority or the academy sponsor. Indeed the only reference to him has been in the local newspaper which ran a story in September, 2013 under the title "Parents in Dark as Headteacher Fails to Return After Summer Holidays". By that time he had not been seen in school for several months and an interim headteacher had been appointed to oversee the school whilst the academy sponsor appointed a new permanent headteacher.

\section{Discussion}

By the end of our research, therefore, the academisation process was complete in that the governing body had been dismissed, a new headteacher was in place and the school was now operating under the sponsorship of an academy chain. In keeping with these changes teachers, support staff and governors appeared resigned (if not committed) to the new governance and management process largely, it seems, on economic grounds for employees and pragmatic grounds for governors and parents. Interestingly the demands normally associated with a school in Special Measures no longer seem to be applied by this stage as government policy appears to be that the future of the school is secure now it has become an academy. In other words now there is apparently no need for regular monitoring by Her Majesty's Inspectors (HMI) which had been the more normal requirement of a school demonstrating improvement. In effect Macademia had been replaced with a wholly new school which thus starting its life with a blank slate, although this is contrary to

\footnotetext{
${ }^{1}$ Name of local newspaper removed for reasons of confidentiality.
} 
previous regulations relating to falling schools which had been required to continue with HMI monitoring even though they had been converted to an academy.

Our research concentrated, however, on the impact of the two concurrent processes of Special Measures and academisation on Macademia School and demonstrated the process had been particularly intense for the headteacher and staff. It appeared that rather than the effects of the two processes merely adding together the effects were multiplied in terms of impact. People who had considered they had done a good job in the past, believed that the school was working well and had faith in what they were doing found themselves under intense scrutiny by these interventions. Participants in this study had thus been exposed to new inspection and legislation that had the inherent capacity to fundamentally change the perceptions of self and their role within the school community at least for the duration of the processes. Ofsted inspection criteria have become increasingly more stringent as time progresses with the reformulation in 2012 of Grade 3, previously held to be indicative of broadly satisfactory performance, into a new category entitled "requiring improvement", thus changed the nature of what is considered to be acceptable performance at both the organisational and individual level. Now, for example, there is no scope for an inspector to make a bland or satisfactory assessment and Ofsted has now determined that the school and/or individual teacher are either Good (or Outstanding) or not. Equally the policy of academisation has always been controversial and has been challenged repeatedly by politicians, commentators, teachers, teachers' unions and parents. Amongst the many criticisms are that they have been selective, divisive and "a move toward privatisation by the back door" (Roberts, 2006). Furthermore a longitudinal study into performance of academies funded by the Local Government Association could find no long term change in performance associated with academy status (Rutt \& Styles, 2013).

The fundamental implication of the amended legislation and inspection regime is that if teachers or schools are not 'Good' (or better), then intervention is required. This means that schools and teachers who cannot or will not become at least 'Good' are likely to be changed, voluntarily or by enactment of new legislation. This is precisely what happened to Macademia as a school and to the members of its community, with interventions to school governance and management and to the operating 
norms of teachers and support staff. Members of the school community had already under pressure, however, as the school did not experience an ordinary and uneventful time between the Ofsted inspections of 2011 and 2012. The overall 'Satisactory' grade awarded in 2011 provided an optimistic picture for the school going forward and acknowledged that significant staffing difficulties of the previous two years had been resolved. With a new senior leadership team having been recently appointed the conditions for "rapid improvement" had been noted at that time (Ofsted, 2011: 13). Compelled to act on the financial situation had led to a whole school restructuring exercise, with number of support staff posts being made redundant in this process and many of those surviving the restructure doing so the cost of a downgrading. The process was lengthy, time consuming and traumatic for all those involved with the result that the headteacher and chair in particular were unable to devote themselves fully to the school's standards agenda. Almost certainly this lack of focus on student performance and teacher capability contributed to the school shifting from 'Satisfactory' to 'Inadequate' albeit that the process was accelerated by the new inspection framework.

The major consequence of the Ofsted grade of 2012, therefore, was detrimental to the self perception of teacher and support staff capability. In a time when they perceived themselves to having made a significant contribution to the financial security of the school they now found themselves in a position of being deemed 'inadequate'. The feelings they subsequently exhibited towards the partner school were largely resentful and exacerbated by suspicions that staff from the appointed school were not providing evidence of practice that was sufficiently different from their own. In this situation the data suggest that teaching and support staff felt undervalued, feelings that perhaps give rise to notions of conspiracy against the local authority and the school with a fair degree of sensitivity evident amongst school employees.

The sense of being undervalued was furthered by the actions of the local authority seemingly not recognising changes made in response to budgetary issues and, in due course, by the Secretary of State enacting legislation to convert Macademia Primary into an academy. The transition to academy status has become a central plank of government policy and there was large degree of inexorability evident in the 
case of Macademia Primary. What seems to have been bypassed, perhaps even overlooked, is the consequence for members of the school communities targeted in this way.

\section{Conclusion}

The senior staff, teachers and support staff investigated in this study were clearly a long way from reconciling themselves to a new regime which was typically perceived as judgmental and unforgiving. Furthermore little was being offered to them to induce and support voluntary change with no evidence apparent that the system (i.e. the policy initiative) or the new leadership structures was paying heed to their concerns and their needs. The biggest losses seem to be with staff motivation and parental engagement. The school had moved from a situation where individual members of staff had previously worked in hope to one where there was fear and a sense of isolation. That is not a good place to be.

\section{References}

Geertz, C. (1973). Thick Description: Toward and Interpretive Theory of Culture: The Interpretation of Cultures. New York: Basic Books.

Humphrey, C (2007). Insider-outsider: Activating the hyphen. Action Research, 5(1), 11-26.

Mercer, J. (2007). The Challenges of Insider Research in Educational Institutions: Wielding a Double-Edged Sword and Resolving Delicate Dilemmas. Oxford Review of Education, 33(1), 1-17.

Ofsted (2011). 'Macadamia' Primary School Inspection Report. London: Ofsted.

Roberts, B. (2006). "Exclusive: Flushed Out". Daily Mirror. (28 ${ }^{\text {th }}$ July) Accessed January 2014.

Rutt, S. and Styles, B. 2013). Analysis of Academy School Performance in the 2011 and 2012 GCSEs (LGA Research Report). Slough: NFER.

Smyth, A., \& Holian, R. (2008). Credibility Issues in Research from within Organisations. In P. Sikes \& A. Potts (Eds.), Researching education from the inside (pp. 33-47). New York, NY: Taylor \& Francis.

Unluer, S. (2012). Being an Insider Researcher While Conducting Case Study Research. The Qualitative Report 17 (58), 1-14. Available at: www.nova.edu/ssss/QR/QR17/unluer.pdf - accessed July, 2014. 